\title{
Study on vertical permeability regularity and collapsibility of a large thickness loess foundation by in-situ testing
}

\author{
Yang Kong ${ }^{1}$, Xuefeng Huang ${ }^{2, a}$, Huaining Ruan ${ }^{1}$, Zhende Zhu ${ }^{1}$ and Chong Shi ${ }^{1}$ \\ ${ }^{1}$ Hohai University, Institute of Geotechnical Engineering, 210098 Nanjing, China \\ ${ }^{2}$ LEU, Department of Architectural Engineering, 401331 Chongqing, China
}

\begin{abstract}
In many regions in China there is a wide distribution of dead-weight collapsible loess that experience frequent disasters resulting in enormous losses to national property. Loess collapsibility is the leading cause of disasters in loess areas. Many international scholars are working collaboratively to avoid property losses and human casualties caused by the collapsible loess. Loess collapsibility is closely related to the vertical permeability regularity, so the vertical permeability regularity should be the first critical factor taken into account in studying loess collapsibility. In Lanzhou city, the in-situ soaking test is carried out on an unsaturated natural loess foundation with a thickness of $36.5 \mathrm{~m}$, the test pit diameter is $40 \mathrm{~m}$, TDR moisture probes are embedded, and the test lasts 282 days. During the test, the vertical migration of water is observed and the temporal and spatial variations of volumetric water content are considered. In the detailed research of the vertical permeability regularity, the relation between permeability regularity and collapsibility are discussed. For shallow layer soil, soil volumetric water content reaches saturation at wetting front, the water flows downward due to gravity and the infiltration rate is larger. For deep layer soil, the moisture will increase because of the upper soil permeability and its own suction, but, due to soil compression caused by the occurrence of the upper soil collapsibility, the infiltration rate is significantly reduced. The temporal and spatial variations of water volumetric content can be used to determine whether a loess collapsible deformation has occurred. The limit permeability depth in this test is $25 \mathrm{~m}$, and the limit permeability depth can also be served as the collapsibility evaluation depth of the unsaturated natural Malan loess foundation.
\end{abstract}

\section{Introduction}

Lack of capital and lack of techniques are important reasons that restrict the development of infrastructure construction in developing countries. China's quest for a social harmonious development is always accompanied with a series of geotechnical engineering problems. It is well known that the unsaturated natural loess is widely distributed in northwest China, and the collapsible characteristic of loess is harmful to the construction of large industrial and civil buildings. A large number of industrial and civil buildings that were built on the collapsible loess foundation have been destroyed, the road pavement has cracked and the water conservancy facilities have failed which caused huge property losses when water flowed into collapsible loess foundation (Liu, 1996). It is an urgent need to find an approach to avoid the damage caused by water permeability. Therefore, it is necessary to study the water permeability regularity on the unsaturated natural loess foundation with the dead-weight collapsible characteristic. Permeability is one of the most important engineering properties of unsaturated natural loess, and many engineering properties such as the size of collapsible deformation value and the collapsible deformation coefficient are all closely related to the permeability. The permeability is mainly reflected in the water flowing regularity. So far, the research on water flow regularity of unsaturated natural loess is far from enough (Liu et al., 2004; Huang and $\mathrm{Li}, 2011$ ).

The experimental method and theoretical calculation of the unsaturated soil permeability coefficient have a certain degree of difficulty (Fredlund, 1993; Chen et al., 2006). The permeability coefficient of unsaturated natural loess is closely related to volumetric water content. The permeability coefficient of unsaturated natural loess can be obtained by direct methods and indirect methods. The indirect methods include the soil water character curve method and the empirical formula method, but its computational accuracy is difficult to grasp. In-situ non-destructive testing of water content is the key testing technique of in-situ soaking test for unsaturated natural loess, which can study the collapsible deformation of unsaturated natural loess and directly get the permeability coefficient.

The TDR method is also called the Domain Reflectometry Time method, which is used to determine the soil dielectric constant and convert it into soil volumetric water content. The theoretical model had been established as early as 1939 , which was initially used in

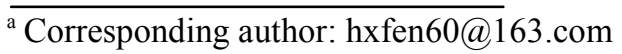


the telecommunication industry to find the cable breakpoint. Monitoring of soil water content was firstly proposed by Canadian scientist, Topp, in 1980, and was used to determine the water content of farmland in 1985 . Compared with the traditional soil volumetric water content testing techniques, it has the advantages of not destroying the sample, is fast, simple and accurate and can be measured continuously with automatic data collection. Since the 1990s, TDR has been used as the basic equipment for testing soil water content (Friel and Or, 1999; Thomsen et al., 2000; Skierucha, 2001; Manoel et al., 2001; Souza and Matsura, 2003; Giraldi and Iannelli, 2009; Scudiero et al., 2012).

In 1963, the hydraulic structure of a Romanian steel industry was built on the dead-weight collapsible loess foundation, which had a thickness of $24 \mathrm{~m}$. The foundation settlement was stable after three months of soaking, and basically eliminated the collapsibility. Soviet construction research institute used the pre-soaking method and the explosion method to encrypt loess at Polos in 1964, after 1 year of soaking, the water content was closed to the natural water content state. Soil tests showed that the loess under a 5 - 6 m depth basically eliminated the collapsibility. As a main research method on collapsible deformation and foundation treatment, the pre-soaking method can reflect the actual soil water flow state and provide the analysis basis for loess permeability regularity research, and these results indoor tests cannot achieve. Since the 1960s, a great number of pre-soaking tests in China have made great contributions to the theoretical research of loess in China and even the world. But studying the permeability regularity of unsaturated natural loess through the large soaking test has rarely been reported. TDR moisture probes are embedded in six artificial exploratory wells in this test to study the loess moisture permeability regularity and the collapsible deformation, so the study has a practical significance.

\section{In-situ tests}

The test site is located in the Peace town of Lanzhou City, Gansu Province, China. Based on the geological prospecting, the geomorphic unit belongs to Huangshui river the southern bank's class- II terrace, and the geomorphic unit is single. According to local deep wells data, the underground stable water depth in this site is greater than $70 \mathrm{~m}$, the total thickness of the soil layer is larger than $38 \mathrm{~m}$, in which collapsible loess's thickness is approximately $36.6 \mathrm{~m}$, and the full thickness soil is collapsible loess. According to the geological examination, it is the Malan loess, and its geotechnical engineering properties are listed in Table 1.

Table 1. Properties of soil layer in test site.

\begin{tabular}{|c|c|c|}
\hline Soil layer & Thickness (m) & Buried depth (m) \\
\hline Cultivated soil $\left(\mathrm{Q}_{3}{ }^{\mathrm{ml}}\right)$ & 0.50 & $0-0.50$ \\
\hline Silt $\left(\mathrm{Q}_{3}{ }^{\mathrm{fl}}\right)$ & 4.50 & $0.50-9.00$ \\
\hline Silty clay $\left(\mathrm{Q}_{3}{ }^{\mathrm{fl}}\right)$ & 31.50 & $1.50-36.00$ \\
\hline Gravel & -- & $>38.0 \mathrm{~m}$ \\
\hline
\end{tabular}

The test pit shape is circular, with a diameter of $40 \mathrm{~m}$, and the diameter length is larger than the thickness of the dead-weight collapsible loess. According to the soil's physical and mechanical indexes of addressed exploration reports and corresponding exploratory wells investigation, there is a homogeneous distribution of soil. There is no adverse geological body, impermeable soil layer or other impurities in the soil of the test site itself or the surroundings.

Six exploratory wells are excavated in both inside and outside of the test pit. Two parallel exploratory wells that have a $5 \mathrm{~m}$ distance from the center are excavated to study the vertical permeability regularity of water. Four wells that are $0 \mathrm{~m}, 5 \mathrm{~m}, 8 \mathrm{~m}$, and $11 \mathrm{~m}$ distance from the test pit edge are excavated to study the level permeability regularity of water. The six exploratory wells are located in one linear cross-section as is shown in Figure 1.

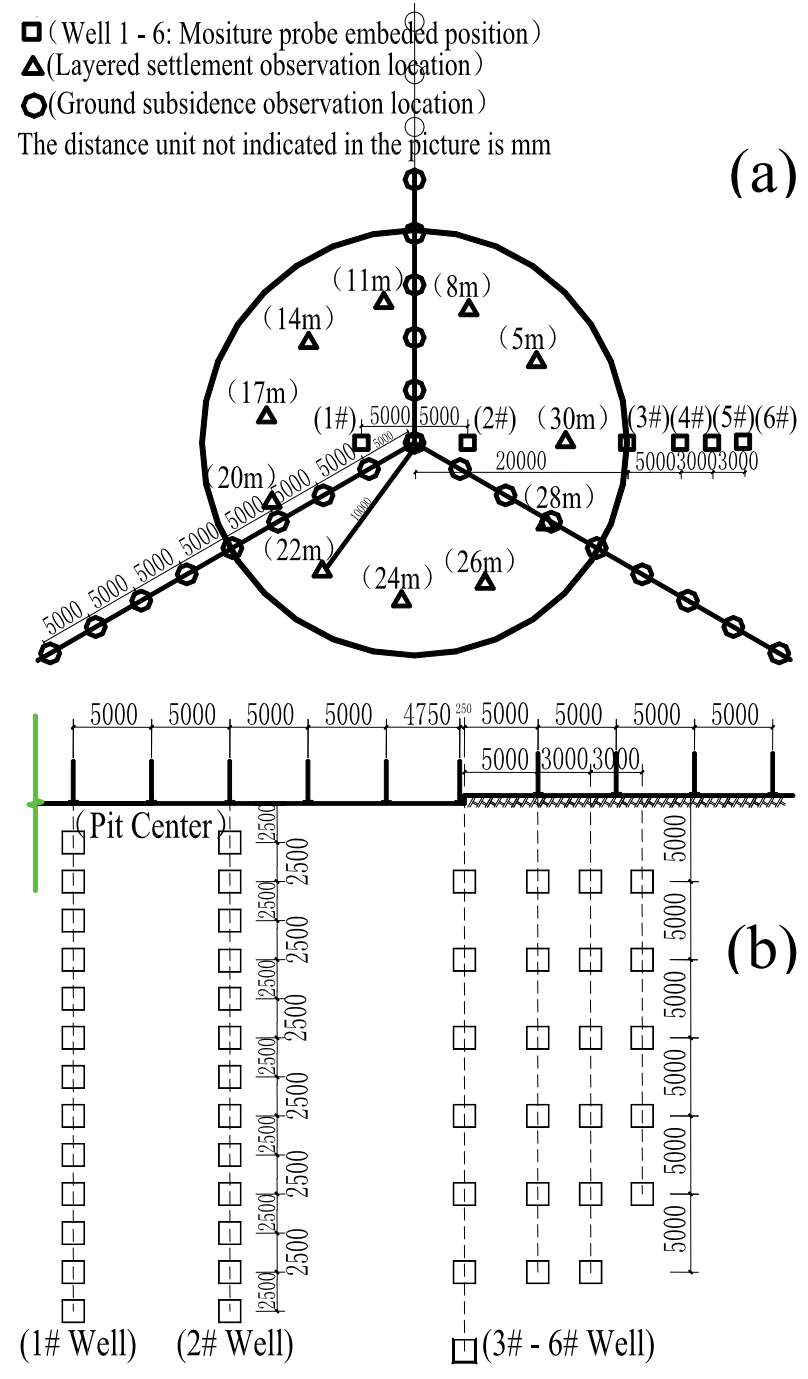

Figure 1. Soaking test arrangement scheme, (a) floor plan and (b) vertical cross-section schematic view.

No.1 and No.2 exploratory wells are embedded with 13 TDR moisture probes, and the distance between each TDR probe is $2.5 \mathrm{~m}$. The number of TDR probes that have been embedded in exploratory wells $3-6$ is respectively $7,6,6$, and 5 . The minimum height TDR probes are embedded at a depth of $2.5 \mathrm{~m}$ or $5.0 \mathrm{~m}$. 
In order to obtain the authentic natural loess test data, above all, some certain vertical exploratory wells of a $32.5 \mathrm{~m}$ length or other lengths and diameter $1.30 \mathrm{~m}$ in the test pit should be excavated. At a certain depth of the exploratory well, the TDR probe should be embedded at the end of a $1.5 \mathrm{~m}$ length and diameter $0.35 \mathrm{~m}$ lateral space that has been excavated by the Luoyang shovel. According to the above method, the TDR moisture probe is buried in the natural soil with the greatest possibility. The TDR moisture probe should be installed with an angle of 45 degrees to reduce the influence caused by poor soil characteristics. The worker should set aside $2 \mathrm{~m}$ extra length cables to ensure that the collapsible loess will not pull out the instrument. The TDR moisture probe installed method as is shown in Figure 2.

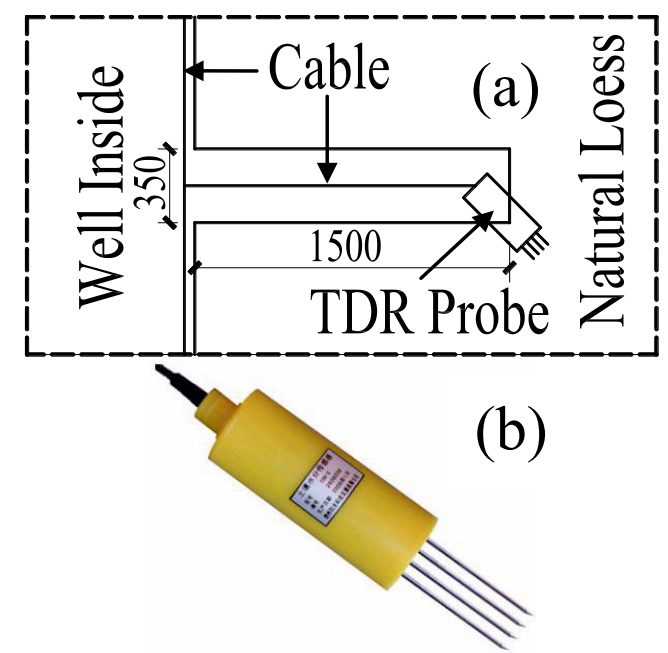

Figure 2. TDR moisture probe installed method, a) installation sketch map and b) a TDR moisture probe.

After the TDR moisture probes are all embedded in a certain well, the exploratory well should be compacted by the rammer, and the compacted density should be slightly larger than the original soil density to prevent the occurrence of embankment collapse. Around the cable and the well surroundings, the isolation water treatment should be done (with 3:7 lime - soil) to prevent downward water penetration along the cable or around the shaft lining.

\section{Test results}

The in-situ soaking test lasts about 282 days on an unsaturated natural loess foundation with a thickness of $36.5 \mathrm{~m}$. The water soaking observation time is 140 days and the water pausing time is 142 days. The soaking test site panorama is shown in Figure 3.

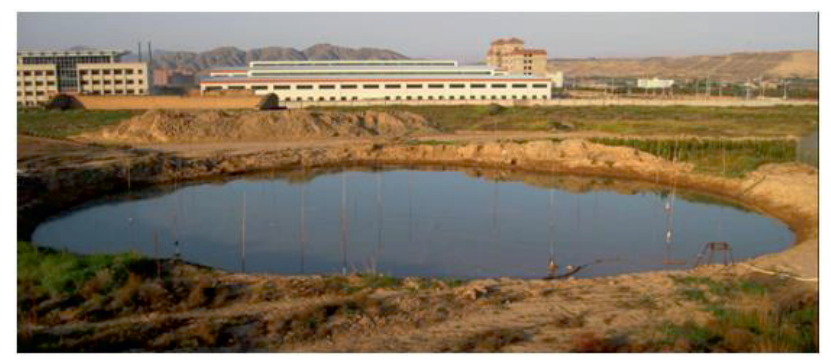

Figure 3. Soaking test site panorama.
According to the above experimental method and the above text depiction, the authors obtained a considerable experimental data of the undisturbed natural loess. The test data measured by the TDR moisture can truly reflect the vertical permeability and the collapsibility of the natural soil.

Because of the limited space, this paper only gives the No.1 exploratory well testing results. The volumetric water content variation curves at different depths and testing stages measured by the TDR moisture probes are shown in Figure $4(\mathrm{a}-\mathrm{m})$. In these figures, the different curve thickness and colours represent the different testing stages.

(a) $2.5 \mathrm{~m} \quad$ Soaking test duration/(d)

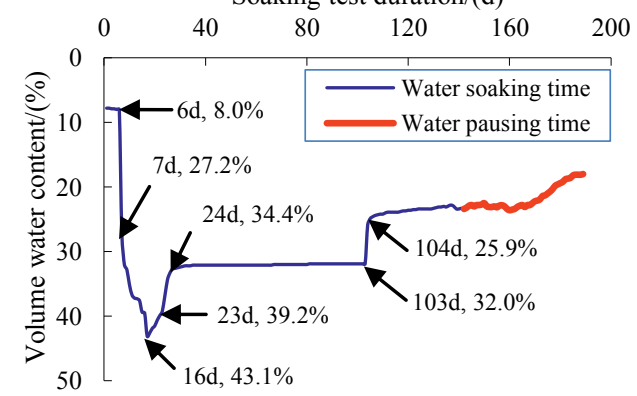

(b) $5.0 \mathrm{~m} \quad$ Soaking test duration/(d)

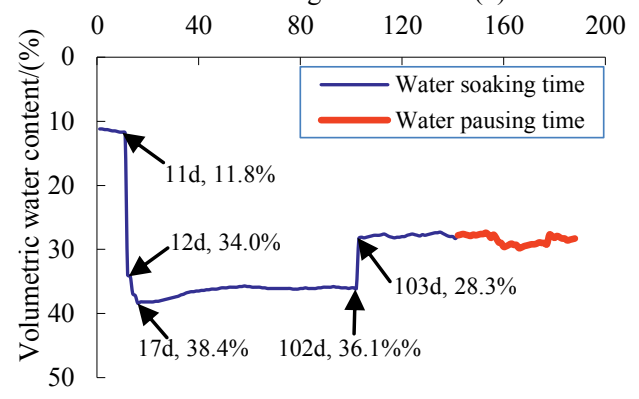

(c) $7.5 \mathrm{~m} \quad$ Soaking test duration/(d)

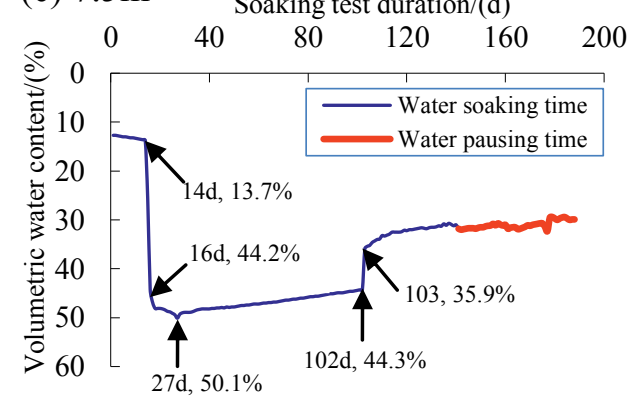

(d) $10.0 \mathrm{~m}$

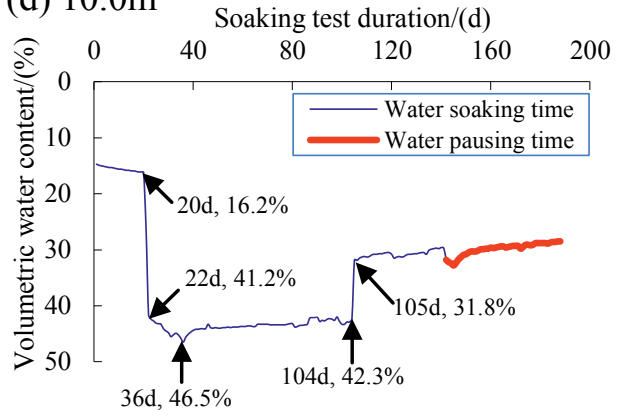


(e) $12.5 \mathrm{~m}$

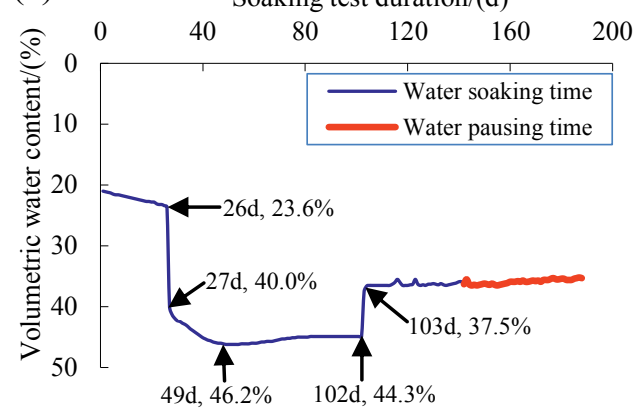

(f) $15.0 \mathrm{~m} \quad$ Soaking test duration/(d)

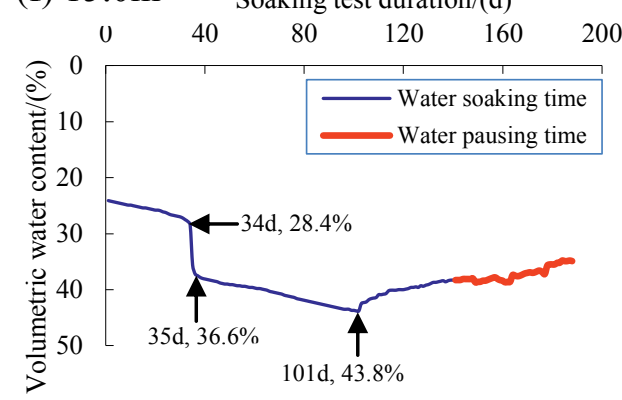

(g) $17.5 \mathrm{~m}$

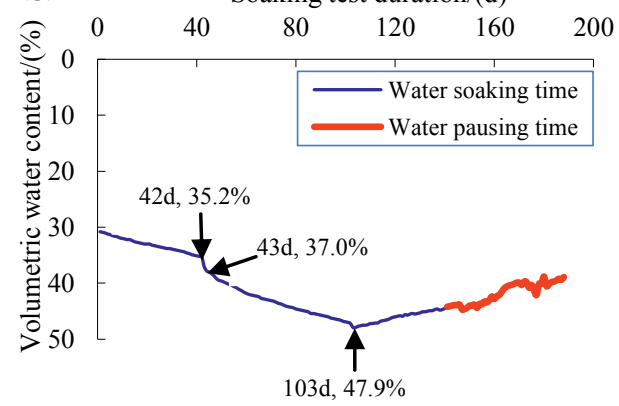

(h) $20.0 \mathrm{~m} \quad$ Soaking test duration/(d)

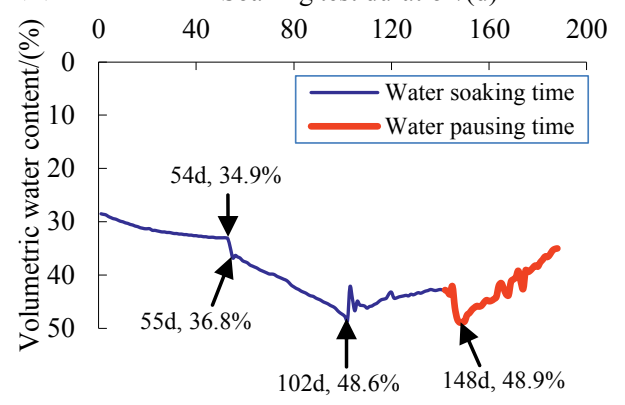

(i) $22.5 \mathrm{~m}$

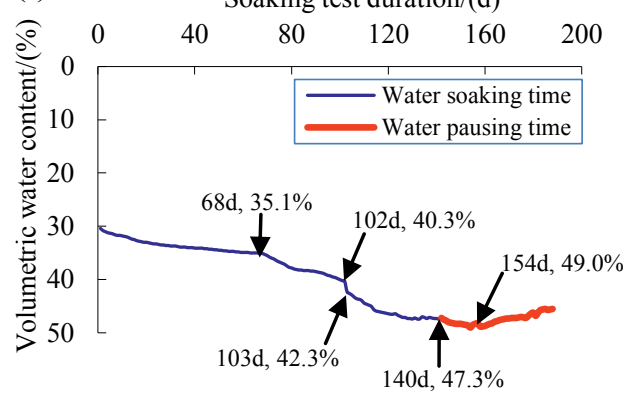

(j) $25.0 \mathrm{~m} \quad$ Soaking test duration/(d)

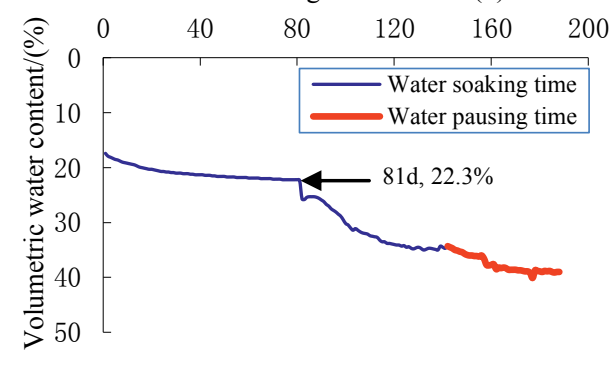

(k) $27.5 \mathrm{~m} \quad$ Soaking test duration/(d)

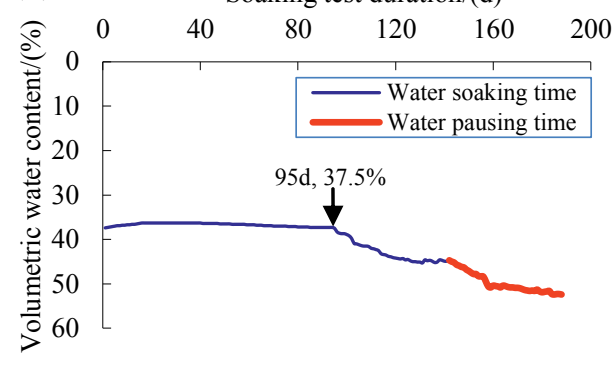

(1) $30.0 \mathrm{~m} \quad$ Soaking test duration/(d)

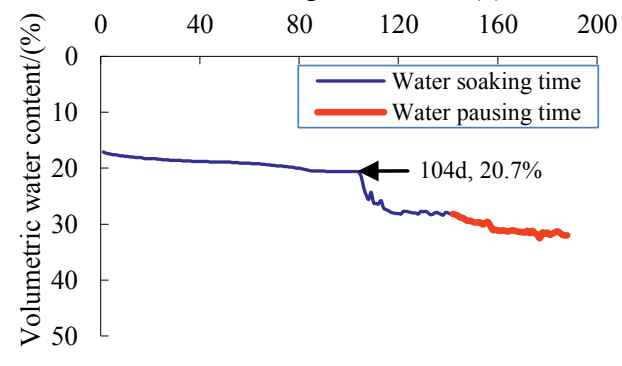

(m) $32.5 \mathrm{~m}$ Soaking test duration/(d)

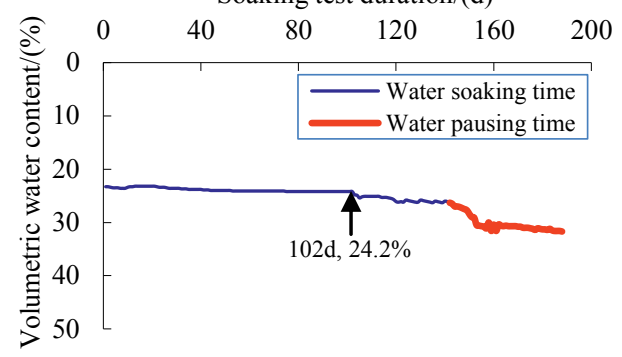

Figure 4. Soil volumetric water content variation curves at different depths and testing stages. Figure 4 (a) - (m) respectively represent depth $2.5-32.5 \mathrm{~m}$.

The variation curve of volumetric water content and soaking duration at depth $2.5 \mathrm{~m}$ in No.1 exploratory well is shown in Figure 4a. As is shown in the figure, the volumetric water content increases steadily to about $8.0 \%$ during the first 6 days, then, the volumetric water content has a rapid increase on the 6th - 7th day, and the volumetric water content increases gradually into the peak water content $39.2 \%$ on the 16 th day (the calculated saturation is larger than $85 \%$ ). The volumetric water content decreases gradually on the 16 th -23 rd day, and 
then the volumetric water content has a rapid decrease on the 23rd - 24th day. The volumetric water content decreases gradually on the 24th - 103rd day, and the volumetric water content has a rapid decrease on the 103rd - 104th day again. After that, the volumetric water content decreases slowly till the end of testing period. From the depiction of Figure $4 \mathrm{a}$, we know that the water reaches the depth $2.5 \mathrm{~m}$ on the 7 th day, and the loess of depth $2.5 \mathrm{~m}$ reaches the saturation on the 16 th day. There are two sudden decreases in the figure, the $23 \mathrm{rd}-24$ th day and the 103rd - 104th day, it is analyzed that the dead-weight collapsible deformation happened on the 23rd - 24th day, and the collapsible deformation happened on the 103rd - 104th day. The reason for this phenomenon is that there is a wet deformation of loess in the period from 7 th -23 rd day, and the loess structural strength decreases gradually. The loess structural strength decreases proportional to the initial dead-weight collapsible pressure till the $23 \mathrm{rd}-24$ th day, so, the soil particle skeleton lost stability and rearranged the particles, led to the stilted particles wedged into the pores of loess, and then followed a dramatically dead-weight collapsible deformation. As the results of the dead-weight collapsible deformation, the loess has a relatively compact and stable structure. From then on, the water weight in the soaking pit is equivalent to the effect of additional load and it is calculated that the influence depth of the additional load has not exceeded $5.0 \mathrm{~m}$. There is a slowly decreasing of strength in the surrounding loess (with a new strength and structure) to the collapsible pressure, accompanied a dramatically collapsible deformation on the 103rd - 104th day. It is found that the dead-weight collapsible deformation and collapsible deformation of loess are the results of the displacements of loess structural units and the permeability movements caused by water flowing into the loess. Figure 4 a shows that development regularity of volumetric water content at depth $2.5 \mathrm{~m}$ can be divided into 6 stages: the initial slow increasing stage, the rapid increasing stage, the rapid decreasing stage, the middle slow decreasing stage, the rapid decreasing stage, the final slow decreasing stage.

The variation curve of volumetric water content and soaking duration at $5.0 \mathrm{~m}$ in No.1 exploratory well is shown in Figure 4b. As is shown in the figure, the volumetric water content increases steadily to about $11.2 \%$ during the first 11 days, then, the volumetric water content has a rapid increase on the 11th - 12th day, and the volumetric water content increases gradually to the peak water content of $38.4 \%$ on the 17 th day. The volumetric water content decreases slowly on the 17 th 102 nd day, and then the volumetric water content has a rapid decrease from $36.1 \%$ to $28.3 \%$ on the 102 nd $103 \mathrm{rd}$ day. It is showed that the collapsible deformation happened on the $102 \mathrm{nd}-103 \mathrm{rd}$ day. Figure $4 \mathrm{~b}-4 \mathrm{e}$ are the variation curves of volumetric water content and soaking duration from the depth $5.0 \mathrm{~m}$ to depth $12.5 \mathrm{~m}$, and these figures have the similar development trend. Figure $4 b-4 e$ show that development regularity of volumetric water content at depth $5.0 \mathrm{~m}-12.5 \mathrm{~m}$ can be divided into 5 stages: the initial slow increasing stage, the rapid increasing stage, the middle slow decreasing stage, the rapid decreasing stage, the final slow decreasing stage.

The variation curves of volumetric water content and soaking duration from the depth $15.0 \mathrm{~m}$ to depth $20.0 \mathrm{~m}$ in No.1 exploratory well are shown in Figure $4 \mathrm{f}-4 \mathrm{~h}$, and these figures have the similar variation regularity. As are shown in Figure 4f, the volumetric water content increases rapidly from $28.4 \%$ to $36.6 \%$ on the 34 th -35 th day, and then the volumetric water content increases gradually to the peak water content $48.8 \%$ on the $101 \mathrm{st}$ day. As is shown in Figure $4 \mathrm{i}$, the volumetric water content increases rapidly from $40.3 \%$ to $42.3 \%$ on the 102 nd - 103rd day, and the volumetric water content increases gradually to the peak water content (saturation) $49.0 \%$ on the 154 th day (water pausing time). According to the analysis before this depth, the variation regularity is dramatically different from the former. After the rapid increase on the 34 th - 35th day, the volumetric water content continues to increase until the peak value, and then maintains a steady decrease. Figure $4 \mathrm{~g}$ and Figure $4 \mathrm{~h}$ have the similar development trend as Figure $4 \mathrm{f}$. The volumetric water content had a small increase in water pausing time at depth $20.0 \mathrm{~m}$ in Figure $4 \mathrm{~h}$, it is estimated that the water infiltrated into the TDR moisture probe from cracks at this point, but this does not alter the water content's steady decreasing trend. Figure $4 \mathrm{f}-4 \mathrm{~h}$ show that development regularity of volumetric water content at depth $15.0 \mathrm{~m}-20.0 \mathrm{~m}$ can be divided into 4 stages: the initial slow increasing stage, the rapid increasing stage, the middle slow increasing stage, and the final slow decreasing stage.

The variation curves of volumetric water content and soaking duration from the depth $25.0 \mathrm{~m}$ to depth $32.5 \mathrm{~m}$ in No. 1 exploratory well are shown in Figure $4 \mathrm{j}-4 \mathrm{~m}$, and these figures have the similar variation regularity. The water content increases continuously from the first day of soaking test, but the variation curves are relatively smooth and it can be divided into three increasing stages. The first stage is the initial stage of the soaking test because the water has not penetrated into the layer, resulting in little change in the volume of water content, almost in a straight line. The second stage is the mid water soaking time and the beginning of the water pausing time. In this stage volumetric water content increases steadily, and the stage water content increment increases significantly. The gradually increasing trend is larger than that of the first phase of increase. The third phase is the volumetric water content stabilization phase of the later water pausing time, but it has always maintained a very slow increasing trend.

In conclusion, loess collapsibility causes structural damages. As a result, the original void is compacted and is accompanied by the volumetric water content decreasing. It is analyzed that the dead-weight collapsible deformation happened on the 23rd - 24th day, and the collapsible deformation happened on the 103rd - 104th day at depth $2.5 \mathrm{~m}$ according to Figure $4 \mathrm{a}$. Figure $4 \mathrm{~b}$ to Figure $4 \mathrm{e}$ reflect that there is a dead-weight collapsible deformation that happened on about the 102nd - 104th day at depth $5.0 \mathrm{~m}-12.5 \mathrm{~m}$ and the extent of dead-collapsible deformation decreases with the increase of depth. It is analyzed that the dead-weight collapsible 
deformation happened on the 101st - 102nd day at depth $15.0 \mathrm{~m}-20.0 \mathrm{~m}$ according to Figure $4 \mathrm{f}-4 \mathrm{~h}$. The degree of dead-weight collapsible deformation decreases with the increase of depth. Figure $4 i$ reflects that a slight dead-weight collapsible deformation happened on about the 154th day at depth $22.5 \mathrm{~m}$, and it is remarkable that it belongs to the water pausing time. In short, although, there is a difference in volumetric water content change process and collapsible deformation process due to the variation of test conditions and soil distributions according to Figure $4 \mathrm{a}-4 \mathrm{i}$, it points out that there is a close relationship between volumetric water content and collapsible deformation. It can be indirectly determined from the TDR moisture probe measured volumetric water content variation curve whether there is a dead-weight collapsible deformation or collapsible deformation, and even study the deformation variation with time.

At a depth of $22.5 \mathrm{~m}$ and a depth smaller than $22.5 \mathrm{~m}$, figures (Figure $4 \mathrm{a}-4 \mathrm{i}$ ) are all ultimately have the symbol of volumetric water content decreasing before the researchers stop recording the data. The volumetric water content in figures (Figure $4 \mathrm{j}-4 \mathrm{~m}$ ) with a depth of $25.0 \mathrm{~m}$ and a depth greater than $25.0 \mathrm{~m}$ has a slow increasing in water pausing time according to the trend of the data after stopping recording. Volumetric water content has kept an increasing trend under the depth of $22.5 \mathrm{~m}$, and the phenomenon indicates that the soil has not reached the saturation point. This is also reflected in the other side that the water permeability is not static on unsaturated natural loess foundation with large thickness, and, with the increase of the soil depth, there is a permeability limited depth. For the shallow soil, water infiltration rate is faster, but for the deeper soil, water infiltration rate is very slow. This is closely related to the occurrence of collapsible deformation of the upper part of the soil. Collapsible deformation caused the compaction of the upper soil layer, and led to voids becoming smaller and, moreover, blocked the further proliferation and permeability of water. The lower part of the soil volumetric continued to increase on the one hand because of the slow soil water permeability in the upper part, on the other hand because of the effect of soil suction.

\section{Conclusions}

An in-situ soaking test is carried out on an unsaturated natural loess foundation with a thickness of $36.5 \mathrm{~m}$, and TDR moisture probes are embedded. During the test, the vertical migration of water is observed. According to the temporal and spatial variation of volumetric water content, the vertical permeability regularity of a large thickness unsaturated natural loess foundation has been cleared, and it can also be used to determine whether there is an occurred loess collapsible deformation. The limit depth of permeability in this test is $25 \mathrm{~m}$, and it served as the collapsible evaluation depth of the unsaturated natural Malan loess foundation, which not only ensures the safety of building foundations, but also reduces construction costs.

\section{Acknowledgements}

The authors would like to thank Dr. Yao, Zhihua and M.S. LIU, Changling for their contributions to this test. The authors would also like to thank B.S. Lisa Gott for her kind help to correct and polish the language.

\section{References}

1. Liu, Z. D. Loess mechanics and engineering (Science and Technology Press of Shanxi, Xian, 1996)

2. Liu, B. J., Xie, Y. L., \& Yu, Y. C. In-site testing study on infiltration in unsaturated loess. Chinese Journal of Rock Mechanics and Engineering, 23(24), 4156-4160 (2004)

3. Huang, X. F., Li, J. Test study on influence of immersion on earth pressure and horizontal displacement of high slope of unsaturated intact loess. Chinese Journal of Rock Mechanics and Engineering, 30(3), 635-642 (2011)

4. Fredlund, D. G., H., Rahardjo. Soils Mechanics for Unsaturated Soils ( John Wiley \& Sons, Ins, 1993)

5. Chen, Z. H., Sun, S. G., Fang, X. W., Zhou, H. Q., Xie, Y. Y. Recent advances of the measuring technology for unsaturated soils and special soils. Chinese Journal of Geotechnical Engineering, 28(2), 147-169 (2006)

6. Friel, R., \& Or, D. Frequency analysis of time-domain reflectometry (TDR) with application to dielectric spectroscopy of soil constituents. Geophysics, 64(3), 707 (1999)

7. Thomsen, a., Hansen, B., \& Schelde, K. Application of TDR to water level measurement. Journal of Hydrology, 236(3-4), 252-258 (2000)

8. Skierucha, W. Accuracy of soil moisture measurement by TDR technique. International Agrophysics, 14, 417-426 (2000)

9. Manoel, C., Vaz, P., \& Hopmans, J. W. Simultaneous measurement of soil penetration resistance and water content with a combined penetrometer - TDR moisture probe. Soil Science Society of America Journal, 65, 4-12 (2001)

10. Souza, C. F., \& Matsura, E. E. Multi-wire time domain reflectometry (TDR) probe with electrical impedance discontinuities for measuring water content distribution. Agricultural Water Management [AGRIC. WATER MANAGE.]., 59(3), 205-216 (2003)

11. Giraldi, D., \& Iannelli, R. Measurements of water content distribution in vertical subsurface flow constructed wetlands using a capacitance probe: benefits and limitations. Desalination, 243(1-3), 182-194 (2009)

12. Scudiero, E., Berti, A., Teatini, P., \& Morari, F. Simultaneous monitoring of soil water content and salinity with a low-cost capacitance-resistance probe. Sensors (Switzerland), 12(12), 17588-17607 (2012) 